\title{
Biorremediação de água residuária têxtil sintética em um sistema combinado constituído por reator biológico e wetland construído
}

\section{Evanleide Rodrigues da Silva ${ }^{1}$, Lucas Olegário Bueno ${ }^{2}$, Leonardo Gomes de Vasconcelos ${ }^{3}$, Rossean Golin ${ }^{4}$ e Eduardo Beraldo de Morais4,*}

\begin{abstract}
${ }^{1}$ Universidade Federal de Mato Grosso. Faculdade de Arquitetura, Engenharia e Tecnologia. Programa de Pós-Graduação em Recursos Hídricos. Av. Fernando Corrêa da Costa, 236. Boa Esperança. Cuiabá-MT, Brasil (CEP 78060-900).

${ }^{2}$ Universidade de São Paulo. Escola de Engenharia de São Carlos. Centro de Recursos Hídricos e Estudos Ambientais. Av. Trabalhador São-Carlense, 400. Parque Arnold Schimidt. São Carlos-SP, Brasil (CEP 13566-590).

${ }^{3}$ Universidade Federal de Mato Grosso. Instituto de Ciências Exatas e da Terra. Departamento de Química. Av. Fernando Corrêa da Costa, 2367. Boa Esperança. Cuiabá-MT, Brasil (CEP 78060-900).

${ }^{4}$ Universidade Federal de Mato Grosso. Faculdade de Arquitetura, Engenharia e Tecnologia. Departamento de Engenharia Sanitária e Ambiental. Av. Fernando Corrêa da Costa, 2367. Boa Esperança. Cuiabá-MT, Brasil (CEP 78060-900). *E-mail: beraldo_morais@yahoo.com.br.
\end{abstract}

Resumo. Um sistema constituído de reator biológico, bioenriquecido com a bactéria Shewanella xiamenensis G5-03, e wetland construído, vegetado com Typha domingensis, foi desenvolvido para o tratamento de água residuária sintética contendo o corante vermelho Congo. O sistema combinado removeu $96,5 \%$ da cor da água residuária, a qual ocorreu principalmente no reator biológico $(83,0 \%)$ devido às condições anaeróbicas favoráveis à clivagem redutiva dos grupos cromóforos do corante. Também foram observadas altas taxas de remoção de turbidez e DQO (89,9\% e 90,6\%, respectivamente), enquanto as taxas de remoção de $\mathrm{PO}_{4}-\mathrm{P}$ e $\mathrm{NH}_{4}-\mathrm{N}$ foram de $70,4 \%$ e $18,3 \%$, respectivamente. 0 wetland construído removeu, em média, 95,7\% de benzidina, um composto carcinogênico que foi gerado no reator biológico a partir da degradação do vermelho Congo, o que pode ter contribuído para a detoxificação parcial da água residuária sintética tratada pelo sistema. Em síntese, o sistema de tratamento avaliado demostrou boa performance na remoção de poluentes da água residuária têxtil sintética.

Palavras-chave: Descoloração; Vermelho Congo; Fitorremediação; Macrófitas; Bioenriquecimento.

Abstract. Bioremediation of synthetic textile wastewater in a combined system constituted by a biological reactor and

Recebido 10/02/2020

Aceito

30/05/2021

Disponível on line $31 / 05 / 2021$

Publicado $31 / 08 / 2021$

Acesso aberto

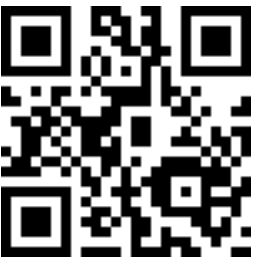

ISSN 2359-1412/RBGAS-2020-0018/2021/8/19/1/675

Rev. Bras. Gest. Amb. Sustent.

http://revista.ecogestaobrasil.net 
constructed wetland. A system constituted by a biological reactor, bioaugmentated with the bacteria Shewanella xiamenensis G5-03, and constructed wetland, vegetated with Typha domingensis, was developed for the treatment of synthetic wastewater containing Congo Red dye. The combined system removed $96.5 \%$ of wastewater color, which occurred mainly in the biological reactor (83.0\%), due to the anaerobic conditions favorable to the reductive cleavage of the chromophore groups of dye. High removal rates of turbidity and COD were also observed (89.9\% and $90.6 \%$, respectively), while $\mathrm{PO}_{4}-\mathrm{P}$ and $\mathrm{NH}_{4}-\mathrm{N}$ removal rates were $70.4 \%$ and $18.3 \%$, respectively. The constructed wetland removed on average $95.7 \%$ of benzidine, a carcinogenic compound that was generated in the biological reactor from Congo red degradation, and this may have contributed to the partial detoxification of the synthetic wastewater treated by the system. In summary, the combined treatment system evaluated has shown good performance in the removal of pollutants from synthetic wastewater.

Keywords: Decolorization; Congo Red; Phytoremediation; Macrophytes; Bioaugmentation.

\author{
ORCID \\ (1) $0000-0002-7294-214 X$ \\ Evanleide Rodrigues \\ da Silva \\ (b) 0000-0001-8099-5295 \\ Lucas Olegário Bueno \\ (1) 0000-0002-2886-1887 \\ Leonardo Gomes de \\ Vasconcelos \\ (1) 0000-0001-9065-1023 \\ Rossean Golin \\ (1) 0000-0002-8505-4133 \\ Eduardo Beraldo de \\ Morais
}

\section{Introdução}

Os corantes têxteis são importantes poluentes ambientais, especialmente de águas superficiais. A maioria deles e seus metabólitos apresentam efeitos tóxicos, mutagênicos e carcinogênicos nos sistemas vivos, e isso é causa de sérios problemas ambientais e de saúde (Puvaneswari et al., 2006). Além disso, as águas residuárias contendo corantes têxteis possuem outros poluentes como surfactantes, ácidos ou bases, metais pesados, sais, sólidos em suspensão e dissolvido e alta concentração de DBO e DQO (Jha et al., 2016; Watharkar et al., 2015). Uma vez descartada em um ecossistema aquático, as águas residuárias coloridas reduzem a penetração da luz solar e a atividade fotossintética, levam à depleção do oxigênio dissolvido e apresentam efeitos tóxicos para a fauna e flora aquáticas (Ali, 2010; Saratale et al., 2011). Assim, métodos eficientes de tratamento para essas águas residuárias devem ser amplamente desenvolvidos.

A biorremediação utilizando bactérias tem se destacado como uma estratégia econômica, ecológica e eficaz para a detoxificação de corantes têxteis (Nachiyar et al., 2014). Esses microrganismos são capazes de processar várias vias metabólicas que podem converter os compostos perigosos, como corantes, em intermediários de baixo peso molecular e estes podem ser completamente mineralizados pela via metabólica central (Balapure et al., 2016).

Recentemente, uma quantidade substancial de pesquisas mostrou a capacidade de várias linhagens de bactérias em descolorir e detoxificar corantes têxteis. Ayed et al. (2011) apontaram que a cepa de Sphingomonas paucimobilis foi capaz de degradar o azo corante Methyl Red em um composto não-tóxico. Saratale et al. (2013) demonstraram que Lysinibacillus sp. RGS degradou e removeu a toxicidade do azocorante Remazol Red. Outras linhagens como Acinetobacter junii FA10, Brevibacillus laterosporus e Bacillus stratosphericus também mostraram a habilidade de descolorir os corantes têxteis Reactive Red-120, Disperse Red 54 e Methyl Orange, respectivamente (Akansha et al., 2019; Anwar et al., 2014; Kurade et al., 2016). Da mesma forma, o potencial promissor da fitorremediação utilizando plantas para remediação de efluentes têxteis é cada vez mais 
reconhecido (Jha et al., 2016). Geralmente, a fitorremediação é feita em sistemas de wetlands construídos, também chamados de sistema de zona úmida, que são baseados no uso de substrato permeável, como cascalho ou areia, comumente plantados com macrófitas emergentes (Shehzadi et al., 2014). O efluente percola o substrato e os poluentes podem ser degradados e removidos pela ação sinérgica entre as raízes das plantas e a microbiota. Diversas espécies vegetais como Phragmites australis, Dracaena sanderiana, Asplenium platyneuron, Typha domingensis, Typha latifolia, Typha angustifolia e Paspalum scrobiculatum (Chandanshive et al., 2017; Saeed; Sun, 2013; Shehzadi et al., 2014; Tee et al., 2015) foram propostas para a remoção de corantes têxteis em wetlands construídos.

Neste estudo, a biorremediação de água residuária sintética contendo o corante azo vermelho Congo foi avaliada em um sistema combinado constituído por reator biológico e wetland construído. 0 reator biológico foi bioenriquecido com Shewanella xiamenensis G5-03, uma bactéria com capacidade de descolorir corantes têxteis, enquanto a zona úmida construída foi plantada com Typha domingensis. 0 vermelho Congo foi usado como um composto modelo no processo de biorremediação porque este corante é metabolizado a benzidina, um carcinógeno humano, e que, apesar disso, tem sido usado não apenas nas indústrias têxteis, mas também nas indústrias de papel, borracha e plásticos.

\section{Material e métodos}

\section{Água residuária sintética}

Água residuária sintética contendo, em g/L, $\mathrm{K}_{2} \mathrm{HPO}_{4} 1,6, \mathrm{KH}_{2} \mathrm{PO}_{4} 0,2,\left(\mathrm{NH}_{4}\right)_{2} \mathrm{SO}_{4} 1,0$, $\mathrm{MgSO}_{4} .7 \mathrm{H}_{2} \mathrm{O} 0,2, \mathrm{FeSO}_{4} .7 \mathrm{H}_{2} \mathrm{O} 0,01, \mathrm{NaCl} 0,1, \mathrm{CaCl}_{2} \mathrm{H}_{2} \mathrm{O}$ 0,02, glicose 1,0, extrato de levedura 1,0 e vermelho Congo 0,05, foi utilizada para alimentar o sistema combinado de tratamento. 0 vermelho Congo foi adquirido de VETEC - Sigma Aldrich, Brasil, e sua estrutura química é apresentada na Figura 1. Todos os demais reagentes químicos utilizados nesse estudo foram de grau analítico.

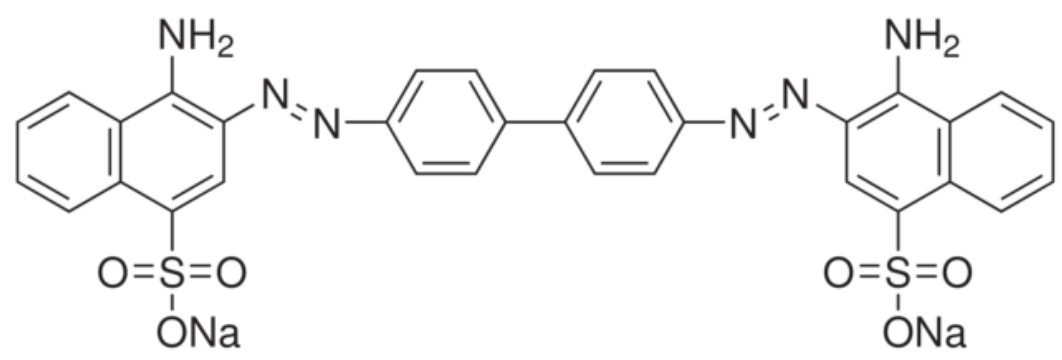

Figura 1. Estrutura química do corante vermelho Congo. Fonte: El Messaoudi et al. (2016).

\section{Meio de cultura e bactéria descolorante}

O meio Caldo Triptona de Soja (TSB) utilizado no cultivo da bactéria descolorante foi adquirido de Himedia Labs e consistiu de (g/L): digerido pancreático de caseína 17,0, digerido papaico de farelo de soja 3.0, cloreto de sódio 5,0, dextrose 2,5, fosfato dipotássico 2,5, pH 7,3 $\pm 0,2$. Agar foi adicionado ao meio TSB $(1,5 \% \mathrm{~m} / \mathrm{v})$ para se obter $\mathrm{o}$ meio Agar Triptona de Soja (TSA). 
A linhagem bacteriana $S$. xiamenensis G5-03 foi previamente isolada de solo do aterro sanitário de Cuiabá-MT, por Cossolin et al. (2019). As culturas estoques desse microrganismo foram rotineiramente mantidas em meio TSA e armazenadas a $4{ }^{\circ} \mathrm{C}$.

\section{Sistema combinado de tratamento em escala de bancada}

O sistema combinado de tratamento consistiu de dois estágios: um reator biológico seguido de um wetland construído de fluxo horizontal subsuperficial (Figura 2).

0 reator biológico foi construído usando tubo de PVC com diâmetro de $15 \mathrm{~cm}$ e $60 \mathrm{~cm}$ de comprimento. Este foi preenchido com pedrisco de dolomita no 1 (diâmetro de 0,5 a $1,0 \mathrm{~cm}$, altura da camada de $35 \mathrm{~cm}$ ) como material suporte para a fixação do biofilme bacteriano. A parte superior do reator foi aberta para a atmosfera. Para o bioenriquecimento do reator biológico com a linhagem bacteriana S. xiamenensis G5-03, esta foi cultivada em TSB no laboratório durante $24 \mathrm{~h}, 35^{\circ} \mathrm{C}$ e agitação (150 rpm). Após, esta cultura crescida da bactéria foi adicionada no reator biológico juntamente com $3,5 \mathrm{~L}$ de TSB estéril. A cada dois dias, durante 15 dias, retirou-se 1,0 L de TSB do reator e adicionou-se 1,0 L de TSB estéril. Após, em um período de 15 dias, o TSB foi substituído gradativamente pela água residuária sintética, sem o corante.

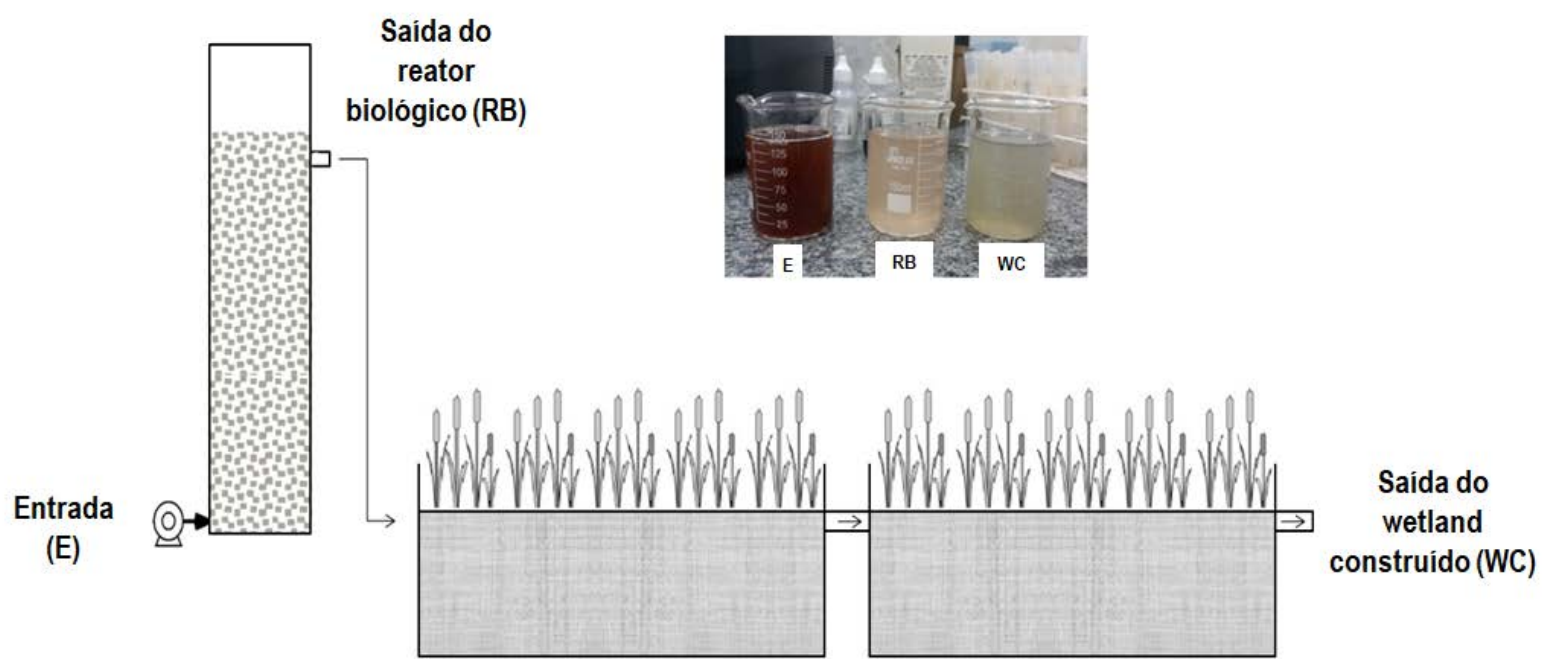

Figura 2. Esquema do sistema combinado para o tratamento de água residuária têxtil sintética. No detalhe os aspectos da água residuária sintética com corante (E), após sua saída do reator biológico (RB) e após a saída do wetland construído (WC).

0 wetland construído de fluxo horizontal subsuperficial foi construído utilizando duas caixas plásticas (81 cm de comprimento, $51 \mathrm{~cm}$ de largura e $29 \mathrm{~cm}$ de altura), montadas em série. Os wetlands foram preenchidos com uma camada de $13 \mathrm{~cm}$ de altura de uma mistura de areia lavada e solo orgânico (1:1). Foram utilizadas pedras do tipo brita no 1 (diâmetro de 0,9 a 1,9 cm) nas regiões de entrada e saída do wetland, a fim de evitar obstruções e homogeneizar o fluxo. Em cada um dos wetlands foram inseridos nove exemplares da macrófita Typha domingensis, as quais foram plantadas de forma equidistantes uma da outra. Os exemplares possuíam tamanhos homogêneos (entre 40-50 $\mathrm{cm}$ ). Foi estabelecido um período de três meses de adaptação, no qual as plantas foram regadas regularmente com água, antes da inserção da água residuária sintética. Após o período de adaptação, a água residuária sintética foi inserida gradualmente sem a inclusão 
de corante por um período de 15 dias, e após esse processo, o corante foi inserido também de forma gradual. Os dados referentes às características volumétricas dos constituintes do sistema de tratamento estão sumarizados na Tabela 1.

Tabela 1. Características volumétricas do sistema combinado de tratamento.

\begin{tabular}{|l|c|c|}
\hline Parâmetro & Reator biológico & Wetland construído \\
\hline Volume total (L) & 10,5 & 119,7 \\
\hline Volume do material suporte (L) & 6,0 & 53,7 \\
\hline Volume de vazios (L) & 4,5 & 25,0 \\
\hline Tempo de detenção hidráulica (h) & 7,8 & 43,8 \\
\hline Porosidade (\%) & 56,6 & 46,5 \\
\hline
\end{tabular}

\section{Operação do sistema}

O sistema foi alimentado com a água residuária sintética contendo o corante com vazão de 9,5 $\mathrm{mL} / \mathrm{min}$ por meio de uma bomba peristáltica, marca Heidolph, modelo PD 5002. 0 fluxo no reator biológico se deu de forma vertical e ascendente, enquanto que no wetland construído o fluxo foi horizontal e subsuperficial. Três pontos de coleta foram estipulados neste experimento: entrada da água residuária sintética no sistema combinado (E), saída do reator biológico (RB) e saída do wetland construído (WC) (Figura 2). Antes de dar início às coletas e análises das amostras, foram feitos testes de vazão, seguidos de 10 dias de aclimatação do efluente no sistema sem adição do corante. Após o período de aclimatação, foi adicionado corante ao efluente, com concentração inicial de $25 \mathrm{mg} / \mathrm{L}$, e posteriormente $50 \mathrm{mg} / \mathrm{L}$. Esse procedimento se estendeu por um período de 20 dias.

\section{Coletas de amostras e métodos analíticos}

0 experimento teve duração de 66 dias e coletas periódicas foram efetuadas nesse período (a cada 5-6 dias). Foram retirados $500 \mathrm{~mL}$ de água residuária sintética em cada ponto de coleta para análises. Os parâmetros analisados foram $\mathrm{pH}$, turbidez, potencial redox, DQO, ortofosfato, sulfato, nitrogênio amoniacal e concentração de vermelho Congo. Os valores de $\mathrm{pH}$ e potencial redox (Eh) foram medidos em aparelho multiparamétrico da marca Hach, modelo HQ40D. As análises de DQO, sulfato $\left(\mathrm{SO}_{4}^{-2}\right)$, nitrogênio amoniacal $\left(\mathrm{NH}_{4}-\mathrm{N}\right)$ e ortofosfato $\left(\mathrm{PO}_{4}-\mathrm{P}\right)$ foram efetuadas de acordo com os métodos do Standard Methods for the Examination of Water and Wastewater (APHA, 2012). A turbidez foi medida em turbidímetro da marca Hach modelo 2100Q. A concentração do vermelho Congo foi determinada em espectrofotômetro UV-Vis, marca Hach, modelo DR600, em $\lambda=$ $497 \mathrm{~nm}$. Para avaliar a remoção de poluentes de cada parte do sistema, foram calculadas as diferenças da concentração dos parâmetros entre a água residuária de entrada, saída do reator biológico e saída do wetland construído. A remoção foi expressa em porcentagem de acordo a Equação (1).

Eficiência de remoção $(\%)=\frac{\text { Valor do parâmetro de entrada-Valor do parâmetro de saída }}{\text { Valor do parâmetro de entrada }} x 100 \quad$ Eq. 1

A benzidina proveniente da clivagem da ligação azo durante a degradação anaeróbia do vermelho Congo foi quantificada nos efluentes do reator biológico e wetland 
construído de acordo com o método colorimétrico pela reação com p-dimetilamino benzaldeído descrito por Oren; Gurevich; Henis (1991). Para isso, foram adicionados 0,8 mL de água mili-Q e 0,05 mL de HCL (1,0 M) em 0,2 mL de amostra. Em seguida foram adicionados $0,5 \mathrm{~mL}$ de p-dimetilamino benzaldeído diluído em $3 \mathrm{~mL}$ de etanol (5\%) e 0,5 mL de ácido cítrico em $\mathrm{NaOH}(6 \%)$. Após $10 \mathrm{~min}, 2,5 \mathrm{~mL}$ de água foram adicionadas aos tubos e a concentração de benzidina foi medida em Espectrofotômetro UV-Vis (Hach, modelo DR6000) a $440 \mathrm{~nm}$.

\section{Testes de fitotoxicidade}

Testes de fitotoxicidade foram efetuados para a avaliar os efeitos tóxicos da água residuária sintética em cada etapa de seu tratamento. Sementes de Cucumis sativus (pepino) foram utilizadas como organismo teste. Dez sementes em uma Placa de Petri $(90$ x $15 \mathrm{~mm}$ ) foram expostas a 5,0 $\mathrm{mL}$ da água residuária por sete dias, $23 \pm 0,3{ }^{\circ} \mathrm{C}$, na ausência de luz. Após esse período, a taxa de germinação (\%), comprimento da radícula $(\mathrm{cm})$ e do hipocótilo $(\mathrm{cm})$ foram mensurados.

\section{Análises estatísticas}

Neste trabalho foi utilizada estatística descritiva para apresentação dos dados. Os resultados são as médias dos parâmetros avaliados no período de estudo \pm desvio padrão. Também são apresentadas as eficiências de remoção (\%) dos parâmetros avaliados em cada etapa do sistema de tratamento assim como a remoção total do sistema combinado. Os resultados para a fitotoxicidade foram avaliados por meio de análise de variância (ANOVA) após constatação da distribuição normal dos dados (quando necessário os dados foram transformados usando logaritmo). As comparações múltiplas das médias foram efetuadas usando o teste de Tukey.

\section{Resultados e discussão}

\section{Desempenho da descoloração}

Durante o tratamento da água residuária sintética com vermelho Congo no reator biológico acrescido de $S$. xiamenensis G5-03 foi observada a remoção de 83,0\% $\pm 7,9$ da cor, enquanto que no wetland construído a remoção foi de $74,2 \% \pm 2,6$. A eficiência total do sistema na remoção da cor foi de $96,5 \% \pm 2,36$ (Tabela 2). Os processos de biodescoloração de corantes por bactérias podem ocorrer em condições anaeróbias, aeróbias ou mediante a combinação destes dois processos (Saratale et al., 2011). Porém, em condições anaeróbias é observado que a remoção da cor ocorre de forma mais eficiente, devido à inibição causada pela presença do oxigênio, o qual compete com o corante pela utilização do NADH para a respiração aeróbia (Chang et al., 2001). A descoloração bacteriana de corantes é realizada pela clivagem redutiva das ligações azo $(-\mathrm{N}=\mathrm{N}-)$, geralmente mediante a presença de uma fonte de carbono, os quais são oxidadas e utilizadas na redução dessas ligações (Stolz, 2001). As azorredutases são as enzimas chaves responsáveis por este processo. A medição do potencial redox da água residuária sintética no reator biológico mostrou que as condições no mesmo foram redutoras o que explica a alta taxa de descoloração nesta unidade (Tabela 2). A descoloração de corantes nestas condições requer uma fonte de carbono e energia orgânica que é, em última instância, responsável pela produção de cofatores enzimáticos reduzidos para a clivagem das ligações azo (Sponza e Işik, 2005). Portanto, a remoção da cor do vermelho Congo pode ser atribuída ao catabolismo da glicose presente na água residuária têxtil sintética.

A implementação do sistema de wetland construído após o reator biológico aumentou a eficiência da remoção da cor da água residuária sintética com o corante. Wetlands construídos oferecem uma gama de possibilidades de remoção de poluentes como sedimentação, filtração, precipitação, adsorção, volatilização, captação pelas plantas 
e principalmente atividade promovida pela microbiota adjacente às raízes (Meng et al., 2014). A remoção do corante no wetland construído ocorreu provavelmente devido às condições anaeróbias que prevaleceram no sistema, aliado à presença da linhagem $S$. xiamenensis G5-03 no substrato do wetland, a qual pode ter se proliferado devido ao fluxo estabelecido no sistema. Além disso, há o incremento da participação das plantas na degradação do corante, devido à produção de enzimas que são liberadas no meio durante o processo de tratamento. Ong et al. (2010) relataram a remoção de 95\% do corante Acid Orange 7 na região anaeróbia de wetlands construídos de fluxo verticais plantados com Phragmites australis e arroz selvagem da Manchúria, destacando a participação das plantas no sistema de tratamento. Por meio das plantas, pode ocorrer absorção dos produtos de degradação, bem como a excreção de componentes que promovem o crescimento e metabolismo dos microrganismos, reforçando a remoção dos poluentes. Assim, a ação sinergética entre bactérias e plantas pode acelerar as reações de degradação (Tee et al., 2015). No caso em estudo, a presença do sistema de wetland construído no tratamento da água residuária têxtil sintética culminou na remoção quase total da coloração proveniente do vermelho Congo.

Tabela 2. Remoção dos poluentes pelo sistema combinado de tratamento. Os resultados são médias \pm desvio padrão de onze amostras.

\begin{tabular}{|c|c|c|c|c|c|c|}
\hline \multirow{2}{*}{ Parâmetros } & \multirow{2}{*}{$\begin{array}{l}\text { Água } \\
\text { residuária } \\
\text { sintética }\end{array}$} & \multicolumn{2}{|c|}{ Reator biológico } & \multicolumn{2}{|c|}{ Wetland construído } & \multirow{2}{*}{$\begin{array}{c}\begin{array}{c}\text { Sistema } \\
\text { combinado }\end{array} \\
\text { Eficiência }(\%)\end{array}$} \\
\hline & & Concentração & $\begin{array}{c}\text { Eficiência } \\
\text { (\%) }\end{array}$ & Concentração & $\begin{array}{c}\text { Eficiência } \\
\text { (\%) }\end{array}$ & \\
\hline $\mathrm{pH}$ & $4,8 \pm 1.1$ & $6,5 \pm 0.5$ & & $7,2 \pm 0.6$ & & \\
\hline $\begin{array}{l}\text { Turbidez } \\
\text { (UNT) }\end{array}$ & $520,7 \pm 184,2$ & $256,8 \pm 96,4$ & $46,5 \pm 23.1$ & $47,1 \pm 21,0$ & $76,0 \pm 20,8$ & $89,9 \pm 5,6$ \\
\hline DQO (mg/L) & $2274 \pm 115,4$ & $1642 \pm 40,1$ & $27,3 \pm 11,0$ & $212,2 \pm 37,1$ & $86,2 \pm 5,7$ & $90,3 \pm 3,8$ \\
\hline $\mathrm{NH}_{4}-\mathrm{N}$ & $178,5 \pm 35,8$ & $224,9 \pm 43,8$ & $-25,9 \pm 19,8$ & $142 \pm 21,8$ & $34,6 \pm 15,3$ & $18,3 \pm 14,7$ \\
\hline $\mathrm{PO}_{4}-\mathrm{P}$ & $855 \pm 494,4$ & $370 \pm 126,8$ & $51,8 \pm 12,2$ & $242,5 \pm 136,6$ & $37 \pm 28,7$ & $70,4 \pm 16,3$ \\
\hline $\mathrm{SO}_{4}^{-2}$ & $238,8 \pm 147,4$ & $4,4 \pm 13,3$ & $98,7 \pm 3,6$ & $4,4 \pm 13,3$ & -- & $99,1 \pm 2,7$ \\
\hline
\end{tabular}

\section{pH e turbidez}

0 valor médio do $\mathrm{pH}$ na água residuária sintética foi de 4,8 (Tabela 2). Esse valor ácido pode ser devido à fermentação da glicose presente na água residuária durante a estocagem da mesma, a qual não se deu em condições estéreis. Ácidos orgânicos são produzidos durante os processos de fermentação, o que pode ter contribuído para a queda do $\mathrm{pH}$. Os valores de $\mathrm{pH}$ aumentaram na saída do reator biológico $(6,5 \pm 0,5)$ e do wetland construído $(7.2 \pm 0.6)$ indicando que os ácidos orgânicos formados na estocagem do efluente foram consumidos pela microbiota durante o tratamento.

O sistema combinado demonstrou alta eficiência na remoção da turbidez $(89,9 \% \pm$ $5,6)$. Os valores médios de turbidez na água residuária sintética, efluente do reator biológico e efluente do wetland construído foram 520,7 $\pm 184,2,256,8 \pm 9,4$ e 47,1 $\pm 21,0$ UNT, respectivamente. 0 substrato presente no wetland possui a capacidade de reter partículas suspensas e presumidamente contribuiu para a redução da turbidez. 


\section{Potencial redox}

0 potencial de óxido-redução tem sido amplamente utilizado como parâmetro controle para identificar ambientes em condições oxidantes (aeróbio) ou redutoras (anaeróbio/anóxico). Por meio deste parâmetro, pode-se prever condições de concentração de oxigênio no sistema, substrato orgânico, atividade dos organismos e alguns compostos tóxicos presentes (Ong et al., 2009). 0 potencial redox está relacionado com a quantidade de elétrons no meio, especialmente com a taxa de íons positivos e negativos, nos quais os potenciais maiores que $100 \mathrm{mV}$ são interpretados como indicativo de ambientes aeróbios, enquanto que valores menores que $-100 \mathrm{mV}$ indicam ambientes anaeróbios (Ong et al., 2010). 0 potencial redox variou de $-103 \mathrm{mV}$ a $-401,1 \mathrm{mV}$ no reator biológico e de $-61,17 \mathrm{mV}$ a $-341 \mathrm{mV}$ no wetland construído, o que favoreceu a clivagem redutiva do corante no sistema. Sabe-se que wetlands construídos de fluxo horizontal são pobres em suprimento de oxigênio, e que este se limita às regiões adjacentes às raízes (Bezbaruah e Zhang, 2004).

\section{Remoção de DQO}

Os poluentes orgânicos foram avaliados por meio da demanda química de oxigênio (DQO), a qual variou de 1484 a $3342 \mathrm{mg} / \mathrm{L}$ na entrada do sistema. A remoção média da DQO no reator biológico foi de $27,3 \% \pm 11,0$ e no wetland construído foi de $86,2 \% \pm 5,7$. A remoção alcançada pelo sistema combinado foi de 90,3\% $\pm 3,8$ (Tabela 2). Observou-se que a remoção de DQO foi maior no wetland construído quando comparada ao reator biológico. Isto pode ser atribuído ao tempo de detenção hidráulica (TDH) estabelecido no reator biológico $(7,8 \mathrm{~h})$ que foi menor do que o do wetland construído $(43,8 \mathrm{~h})$. Vários estudos relataram que existe uma relação positiva entre a remoção de DQO e o TDH (Balapure et al., 2016; Brás et al., 2005; Firmino et al., 2010). Kapdan e Alparslan (2005) observaram que houve aumento da eficiência na remoção da DQO, de 30\% para 75\%, com o aumento do TDH de $12 \mathrm{~h}$ para $48 \mathrm{~h}$ em um reator anaeróbio de leito fixo. Da mesma forma, Işik e Sponza (2005) obtiveram um aumento de 29,4\% para 79,9\% quando estenderam o tempo de detenção hidráulica de $6 \mathrm{~h}$ para $100 \mathrm{~h}$ em um reator UASB utilizando uma mistura de cinco corantes têxteis. Porém, resultados encontrados por Firmino et al., (2010) relatam que o tempo de contato do efluente com os produtos de degradação do corante têxtil também pode afetar na remoção da DQO. Sponza e Işik (2005) apresentaram resultados que corroboraram com essa hipótese durante um experimento em um reator UASB e o corante Reactive Black 5, no qual a remoção da DQO aumentou de $40,8 \%$ para $56 \%$, quando o TDH foi reduzido de $30 \mathrm{~h}$ para $15,5 \mathrm{~h}$. A conclusão é de que a remoção de DQO em fases anaeróbias varia bastante, podendo aumentar ou diminuir de acordo com o TDH, porém o tempo de contato com os metabólitos tóxicos provenientes da degradação do corante pode refletir na eficiência da remoção, caracterizando o ambiente anaeróbio como sendo eficiente na remoção de cor, porém, pode não contribuir significantemente na remoção de DQO. Portanto, uma segunda etapa para remoção de DQO e de metabólitos oriundos da degradação do corante se faz necessária.

Wetlands construídos possuem grande eficiência na remoção de matéria carbonácea, que pode ser degradada em ambas as condições aeróbias e anaeróbias por organismos heterotróficos presentes a depender da concentração do oxigênio existente no leito. O suprimento de oxigênio necessário ao processo de degradação aeróbia em wetlands é fornecido pela translocação com a atmosfera e também pela superfície das raízes das macrófitas (Bezbaruah e Zhang, 2004). De acordo com Ong et al. (2010) a captação da matéria orgânica pelas macrófitas é ínfima quando comparada à biodegradação. Com isso, o tempo de detenção hidráulica estabelecido no sistema wetland construído $(43,8 \mathrm{~h})$ pode ter incrementado a remoção de matéria orgânica, que é utilizada principalmente pelos microrganismos associados às plantas e ao substrato. 


\section{Remoção de nutrientes}

Em relação às concentrações de $\mathrm{NH}_{4}-\mathrm{N}$ houve aumento após a passagem da água residuária sintética pelo reator biológico $(25,9 \% \pm 19,8 \%)$ (Tabela 2), que ocorreu provavelmente devido à amonificação dos compostos nitrogenados presentes, sob condições anaeróbias. Uma vez que o próprio vermelho Congo possui diversos grupos aminas, a desaminação destes também levam a formação de amônia. Houve remoção de $\mathrm{NH}_{4}-\mathrm{N}$ apenas no wetland construído $(34,6 \% \pm 15,3 \%)$. Isto se deve à captação pelas plantas emergentes e crescimento de microrganismos em torno do sistema de raízes, que aliado ao suprimento de oxigênio nessa região, podem produzir um efeito positivo nas bactérias nitrificantes presentes na rizosfera. Outra possibilidade que deve ser considerada é a desnitrificação uma vez que foi constada condições anaeróbicas no reator biológico e wetland construído necessárias para esse processo.

Devido ao incremento da concentração de amônia na saída do reator biológico, a remoção total desse composto no sistema combinado somou 18,3\% $\pm 14,7 \%$. Ong et al., (2009) verificaram o mesmo efeito utilizando wetlands de fluxo vertical plantados com arroz da Manchúria e Phragmites australis, no qual o ambiente anóxico encontrado no fundo dos reatores inibiu as reações de nitrificação, causando um aumento na concentração de $\mathrm{NH}_{4}-\mathrm{N}$ nas regiões em que foram detectadas baixas concentração de oxigênio. Isso explica o aumento da concentração de $\mathrm{NH}_{4}-\mathrm{N}$ no reator biológico, no qual foram detectados valores baixos de potencial de óxido-redução.

A remoção de fósforo foi de $51,8 \% \pm 12,2 \%$ no reator biológico, seguida de $37,0 \%$ $\pm 28,7 \%$ no wetland construído. A remoção total pelo sistema combinado foi de $70,4 \% \pm$ 16,3\%. A remoção de fosfato é alcançada por processos químicos, físicos e biológicos. Em wetlands construídos, ela pode variar de acordo com a escolha do substrato e também da espécie vegetal. A retenção de fósforo costuma ser baixa em todos os tipos de wetlands construídos, e a maioria dos estudos demonstram acúmulo de fósforo no solo (Vymazal, 2007). Ong et al. (2010) encontraram uma remoção de fósforo de $52 \%$ em wetland construído plantado com arroz da Manchúria, 34\% em wetland plantado com Phragmites autralis e $36 \%$ em wetland não vegetado, indicando que diferentes espécies podem apresentar diferentes perfis de remoção de fósforo. Além disso, microrganismos e algas presentes em sistemas wetlands podem utilizar fósforo na composição de seus tecidos.

A provável redução do sulfato à sulfeto ocorreu quase que totalmente no reator biológico (98,7\%), indicando a presença de bactérias redutoras de sulfato no sistema. 0 gênero Shewanella é conhecido pela versatilidade metabólica, sendo capaz de utilizar vários compostos como aceptores de elétrons (Hau e Gralnick, 2007). Tais bactérias são caracterizadas também por conseguirem crescer em anaerobiose na presença de sulfato. Elas podem produzir sulfeto de hidrogênio $\left(\mathrm{H}_{2} \mathrm{~S}\right)$ e são altamente resistentes na sua presença (Moser e Nealson, 1996).

\section{Remoção de benzidina}

Como resultado da descoloração de corantes azo são formadas aminas aromáticas tóxicas (Stolz, 2001). Durante a descoloração do vermelho Congo, um dos produtos gerados corresponde à benzidina, que é considerada uma amina aromática carcinogênica, e por isso, foi avaliada durante o tratamento da água residuária sintética no sistema combinado. A concentração da benzidina na saída do reator biológico variou de 2,60 a $12,70 \mathrm{mg} / \mathrm{L}$, enquanto no wetland construído a variação foi de 0,0 a 1,06 mg/L (Figura 3). A taxa média de remoção foi de $95,7 \% \pm 5,0 \%$, o que indica que o wetland construído foi eficiente na retenção e/ou degradação dessa amina aromática. 


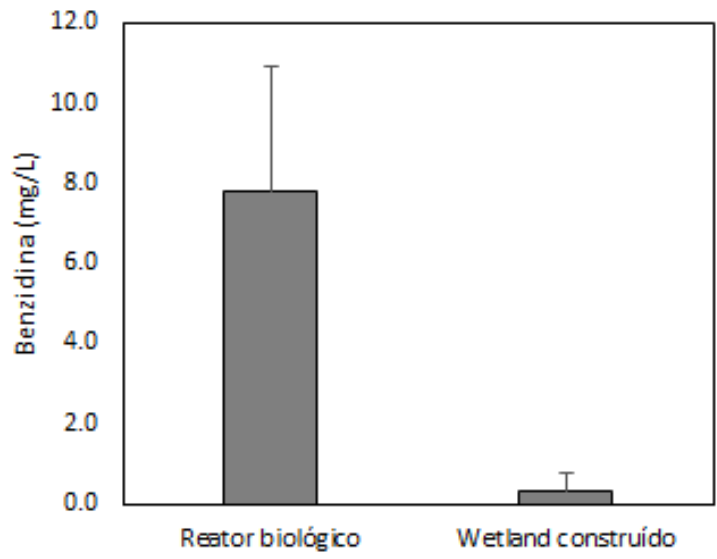

Figura 3. Remoção de benzidina no sistema combinado de tratamento de água residuária têxtil sintética. Os resultados são médias \pm desvio padrão de 11 amostras.

As aminas aromáticas, com poucas exceções, não são mineralizadas anaerobicamente, porém são rapidamente degradadas em condições aeróbias. A degradação das aminas aromáticas no wetland construído provavelmente é possível devido à existência de condições aeróbicas nas zonas próximas às raízes. Os resultados encontrados nesse estudo possuem importantes implicações para o ambiente pois o sistema de tratamento avaliado foi capaz de remover benzidina com alta eficiência, podendo ser uma alternativa para o tratamento de águas residuárias têxteis.

\section{Fitotoxicidade}

Os compostos produzidos a partir da degradação dos corantes geralmente são mais tóxicos do que o composto original (Balapure et al., 2016; Lade et al., 2012). Assim, durante estudos de biodescoloração se faz necessário a avaliação da toxicidade dos corantes e os metabólitos de sua degradação. Neste estudo, ensaios de fitotoxicidade, avaliação da germinação da semente e crescimento da planta, foram efetuados usando Cucumis sativus (pepino) como organismo teste. A aplicação de ensaios de fitotoxicidade para o monitoramento dos efeitos tóxicos de corantes tem sido propostos por diversos pesquisadores devido a simplicidade e baixo custo (Akansha et al., 2019; Khandare et al., 2013; Lade et al., 2012). A Figura 4 apresenta os resultados obtidos para taxa de germinação das sementes assim como os comprimentos médios das radículas e hipocótilos para as diferentes amostras. A germinação das sementes foi inibida em amostras coletadas em todas as etapas do tratamento (entrada do sistema e saídas do reator biológico e wetland construído) (Figura 4a). Em relação ao desenvolvimento da planta, foi observado que a inibição do crescimento da radícula e hipocótilo diminuiu no efluente do wetland construído, comparado às outras etapas do tratamento. Os comprimentos médios da radícula na entrada do sistema, saída do reator biológico e saída do wetland construído foram $0,70 \mathrm{~cm} \pm 0,60 \mathrm{~cm}, 1,06 \mathrm{~cm} \pm 0,80 \mathrm{~cm}$, e $1,82 \mathrm{~cm} \pm 1,08 \mathrm{~cm}$, respectivamente, enquanto que os comprimentos médios do hipocótilo foram de $0,81 \mathrm{~cm} \pm 0,61 \mathrm{~cm}, 0,84 \mathrm{~cm} \pm 0,56 \mathrm{~cm}$, e $2,27 \mathrm{~cm} \pm 1,58 \mathrm{~cm}$, respectivamente (Figuras $4 \mathrm{~b}$ e 4c). Tais resultados indicam uma detoxificação parcial da água residuária sintética. Deve ser destacado que além dos metabólitos provenientes da degradação do corante, outros compostos também podem conferir toxicidade à água residuária, especialmente amônia e sulfeto. 

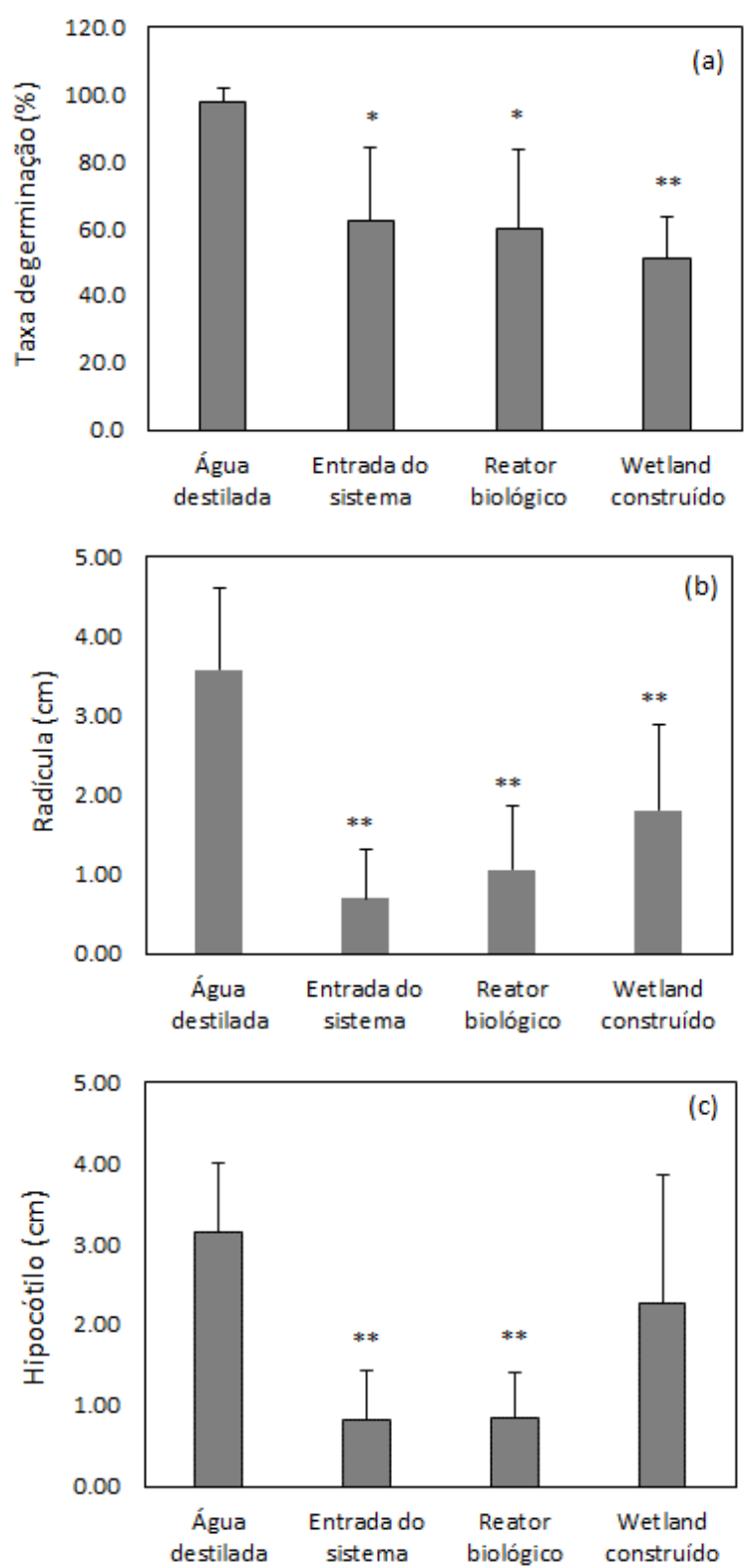

Figura 4. Estudo de fitotoxicidade da água residuária sintética contendo o corante vermelho Congo durante seu tratamento em sistema combinado de reator biológico e wetland construído. Os resultados são médias \pm desvio padrão de oito amostras. As sementes germinadas nas amostras na entrada do sistema, reator biológico e wetland construído são significativamente diferentes das sementes germinadas na água destilada quando ${ }^{*} p<0,05 \mathrm{e}^{* *} p<0,01$.

\section{Conclusão}

Um sistema combinado por reator biológico bioenriquecido com a bactéria Shewanella xiamenensis G5-03 e por wetland construído contendo a macrófita Typha domingensis foi desenvolvido para tratar águas residuais têxteis sintéticas contendo o corante azo vermelho Congo. 0 sistema foi eficiente na remoção da cor (remoção acima de 96\%). Altas taxas de remoção de turbidez e DQO também foram observadas $(89,9 \%$ e $90,6 \%$, respectivamente), enquanto as taxas de remoção de $\mathrm{PO}_{4}-\mathrm{P}$ e $\mathrm{NH}_{4}-\mathrm{N}$ atingiram $70,4 \%$ e $18,3 \%$, respectivamente. 0 wetland construído mostrou-se eficiente em remover 
benzidina, uma amina aromática carcinogênica formada a partir da degradação do vermelho do Congo. Em conclusão, as estratégias biotecnológicas, como a biorremediação e a fitorremediação, podem ser promissoras para o tratamento de efluentes têxteis.

\section{Agradecimentos}

O presente trabalho foi realizado com apoio da Coordenação de Aperfeiçoamento de Pessoal de Nível Superior - Brasil (CAPES) - Código de Financiamento 001, e o apoio do Conselho Nacional de Desenvolvimento Científico e Tecnológico (CNPq), Processo $\mathrm{n}^{\mathrm{o}}$ 486168/2013-1.

\section{Conflito de interesses}

Os autores declaram não haver conflitos de interesse.

\section{Referências}

APHA - American Public Health Association. Standard methods for the examination of water and wastewater. 22. ed. Washington: APHA, AWWA, WEF, 2012.

Akansha, K.; Chakraborty, D.; Sachan, S. G. Decolorization and degradation of methyl orange by Bacillus stratosphericus SCA1007. Biocatalysis and Agricultural Biotechnology, v. 18, 101044, 2019. https://doi.org/10.1016/j.bcab.2019.101044

Ali, H. Biodegradation of synthetic dyes: A review. Water, Air \& Soil Pollution, v. 213, n. 1/4, p. 251-273, 2010. https://doi.org/10.1007/s11270-010-0382-4

Anwar, F.; Hussain, S.; Ramzan, S.; Hafeez, F.; Arshad, M.; Imran, M.; Maqbool, Z.; Abbas, N. Characterization of reactive red-120 decolorizing bacterial strain Acinetobacter junii FA10 capable of simultaneous removal of azo dyes and hexavalent chromium. Water, Air \& Soil Pollution, v. 225, n. 8, 2014. https://doi.org/10.1007/s11270-014-2017-7

Ayed, L.; Mahdhi, A.; Cheref, A.; Bakhrouf, A. Decolorization and degradation of azo dye Methyl Red by an isolated Sphingomonas paucimobilis: Biotoxicity and metabolites characterization. Desalination, v. 274, n. 1/3, p. 272-277, 2011. https://doi.org/10.1016/ j.desal.2011.02.024

Balapure, K.; Jain, K.; Bhatt, N.; Madamwa, D. Exploring bioremediation strategies to enhance the mineralization of textile industrial wastewater through sequential anaerobicmicroaerophilic process. International Biodeterioration and Biodegradation, v. 106, p. 97-105, 2016. https://doi.org/10.1016/j.ibiod.2015.10.008

Bezbaruah, A. N.; Zhang, T. C. pH, redox, and oxygen microprofiles in rhizosphere of bulrush (Scirpus validus) in a constructed wetland treating municipal wastewater. Biotechnology and Bioengineering, v. 88, n. 1, p. 60-70, 2004. https://doi.org/10.1002/ bit.20208

Brás, R.; Gomes, A.; Ferra, M. I. A.; Pinheiro, H. M.; Gonçalves, I. C. Monoazo and diazo dye decolourisation studies in a methanogenic UASB reactor. Journal of Biotechnology, v. 115, n. 1, p. 57-66, 2005. https://doi.org/10.1016/j.jbiotec.2004.08.001

Chandanshive, V. V.; Rane, N. R.; Tamboli, A. S.; Gholave, A. R.; Khandare R. V.; Govindwar, S. P. Co-plantation of aquatic macrophytes Typha angustifolia and Paspalum scrobiculatum for effective treatment of textile industry effluent. Journal of Hazardous Materials, v. 338, p. 47-56, 2017. https://doi.org/10.1016/j.jhazmat.2017.05.021 
Chang, J. S.; Chou, C.; Lin, Y. C.; Lin, P. G.; Ho, J. Y.; Hu, T. L. Kinetic characteristics of bacterial azo-dye decolorization by Pseudomonas luteola. Water Research, v. 35, n. 12, p. 2841-2850, 2001. https://doi.org/10.1016/S0043-1354(00)00581-9

Cossolin, A. S.; Reis, H. C. O.; Castro, K. C.; Santos, B. A. P.; Marques, M. Z.; Parizotto, C. A.; Dall'Oglio, E. L.; Vasconcelos, L. G.; Morais, E. B. Decolorization of textile azo dye Reactive Red 239 by the novel strain Shewanella xiamenensis G5-03 isolated from contaminated soil. Revista Ambiente \& Água, v. 14, n. 6, p. 1-11, 2019. https://doi.org/10.4136/ambiagua.2446

El Messaoudi, N.; El Khomri, M.; Dbik, A.; Bentahar, S.; Lacherai, A.; Bakiz, B. Biosorption of Congo red in a fixed-bed column from aqueous solution using jujube shell: Experimental and mathematical modeling. Journal of Environmental Chemical Engineering, v. 4, n. 4, p. 3848-3855, 2016. https://doi.org/10.1016/j.jece.2016.08.027

Firmino, P. I. M.; Silva, M. E.; R.; Cervantes, F. J.; Santos, A. B. Colour removal of dyes from synthetic and real textile wastewaters in one- and two-stage anaerobic systems. Bioresource Technology, v. 101, n. 20, p. 7773-7779, 2010. https://doi.org/10.1016/ j.biortech.2010.05.050

Hau, H. H.; Gralnick, J. A. Ecology and biotechnology of the Genus Shewanella. Annual Review of Microbiology, v. 61, n. 1, p. 237-258, 2007. https://doi.org/10.1146/ annurev.micro.61.080706.093257

Işik, M.; Sponza, D. T. Substrate removal kinetics in an upflow anaerobic sludge blanket reactor decolorising simulated textile wastewater. Process Biochemistry, v. 40, n. 3/4, p. 1189-1198, 2005. https://doi.org/10.1016/j.procbio.2004.04.014

Jha, P.; Jobby, R.; Desai, N. S. Remediation of textile azo dye acid red 114 by hairy roots of Ipomoea carnea Jacq. and assessment of degraded dye toxicity with human keratinocyte cell line. Journal of Hazardous Materials, v. 311, p. 158-167, 2016. https://doi.org/ 10.1016/j.jhazmat.2016.02.058

Kapdan, I. K.; Alparslan, S. Application of anaerobic-aerobic sequential treatment system to real textile wastewater for color and COD removal. Enzyme and Microbial Technology, v. 36, n. 2/3, p. 273-279, 2005. https://doi.org/10.1016/j.enzmictec.2004.08.040

Khandare, R. V.; Kabra, A. N.; Kadam, A. A.; Govindwar, S. P. Treatment of dye containing wastewaters by a developed lab scale phytoreactor and enhancement of its efficacy by bacterial augmentation. International Biodeterioration and Biodegradation, v. 78, p. 89-97, 2013. https://doi.org/10.1016/j.ibiod.2013.01.003

Kurade, M. B.; Waghmode, T R.; Khandare, R. V.; Jeon, B. H.; Govindwa, S. P. Biodegradation and detoxification of textile dye disperse Red 54 by Brevibacillus laterosporus and determination of its metabolic fate. Journal of Bioscience and Bioengineering, v. 121, n. 4, p. 442-449, 2016. https://doi.org/10.1016/j.jbiosc.2015.08.014

Lade, H. S.; Waghmode, T. R.; Kadam, A. A.; Govindwa, S. P. Enhanced biodegradation and detoxification of disperse azo dye Rubine GFL and textile industry effluent by defined fungal-bacterial consortium. International Biodeterioration \& Biodegradation, v. 72, p. 94-107, 2012. https://doi.org/10.1016/j.ibiod.2012.06.001

Meng, X.; Liu, G.; Zhou, J.; Fu, Q. S. Effects of redox mediators on azo dye decolorization by Shewanella algae under saline conditions. Bioresource Technology, v. 151, p. 63-68, 2014. https://doi.org/10.1016/j.biortech.2013.09.131 
Moser, D. P.; Nealson, K. H. Growth of the facultative anaerobe Shewanella putrefaciens by elemental sulfur reduction. Applied and Environmental Microbiology, v. 62, n. 6, p. 2100-2105, 1996.

Nachiyar, C. V.; Namasivayam, S. K. R.; Kumar, R. R.; Sowjanya, M. Bioremediation of textile effluent containing Mordant Black 17 by bacterial consortium CN-1. Journal of Water Process Engineering, v. 4, n. C, p. 196-200, 2014. https://doi.org/10.1016/ j.jwpe.2014.10.003

Ong, S. A.; Uchiyama, K.; Inadama, D.; Yamagiwa, K. Simultaneous removal of color, organic compounds and nutrients in azo dye-containing wastewater using up-flow constructed wetland. Journal of Hazardous Materials, v. 165, n. 1/3, p.696-703, 2009. https://doi.org/10.1016/j.jhazmat.2008.10.071

Ong, S. A.; Uchiyama, K.; Inadama, D.; Yuji Ishida, Y.; Yamagiwa, K. Performance evaluation of laboratory scale up-flow constructed wetlands with different designs and emergent plants. Bioresource Technology, v. 101, n. 19, p. 7239-7244, 2010. https://doi.org/ 10.1016/j.biortech.2010.04.032

Oren, A.; Gurevich, P.; Henis, Y. Reduction of nitrosubstituted aromatic compounds by the halophilic anaerobic Eubacteria Haloanaerobium praevalens and Sporohalobacter marismortui. Applied and Environmental Microbiology, v. 57, n. 11, p. 3367-3370, 1991.

Puvaneswari, N.; Muthukrishnan, J.; Gunasekaran, P. Toxicity assessment and microbial degradation of azo dyes. Indian Journal of Experimental Biology, v. 44, p. 618-626, 2006.

Saeed, T.; Sun, G. A lab-scale study of constructed wetlands with sugarcane bagasse and sand media for the treatment of textile wastewater. Bioresource Technology, v. 128, p. 438-447, 2013. https://doi.org/10.1016/j.biortech.2012.10.052

Saratale, R. G.; Saratale, G. D.; Chang, J. S.; Govindwar, S. P. Bacterial decolorization and degradation of azo dyes: A review. Journal of the Taiwan Institute of Chemical Engineers, v. 42, n. 1, p. 138-157, jan. 2011. https://doi.org/10.1016/j.jtice.2010.06.006

Saratale, R. G.; Gandhi, S. S.; Purankar, M. V.; Kurade, M. B.; Govindwar, S. P.; Oh, S. E.; Saratale, G. D. Decolorization and detoxification of sulfonated azo dye C.I. Remazol Red and textile effluent by isolated Lysinibacillus sp. RGS. Journal of Bioscience and Bioengineering, v. 115 , $\quad$ n. 6 , p.658-667, 2013. https://doi.org/10.1016/ j.jbiosc.2012.12.009

Shehzadi, M.; Afzal, M.; Khan, M. U.; Islam, E.; Mobin, A.; Anwar, S.; Khan, Q. M. Enhanced degradation of textile effluent in constructed wetland system using Typha domingensis and textile effluent-degrading endophytic bacteria. Water Research, v. 58, p. 152-159, 2014. https://doi.org/10.1016/j.watres.2014.03.064

Sponza, D. T.; Ișik, M. Toxicity and intermediates of C.I. Direct Red 28 dye through sequential anaerobic/aerobic treatment. Process Biochemistry, v. 40, n. 8, p. 2735-2744, 2005. https://doi.org/10.1016/j.procbio.2004.12.016

Stolz, A. Basic and applied aspects in the microbial degradation of azo dyes. Applied Microbiology and Biotechnology, v. 56, n. 1/2, p. 69-80, 2001.

Tee, H. C.; Lim, P. E.; Seng, C. E.; Nawi, M. A. M.; Adnan, R. Enhancement of azo dye Acid Orange 7 removal in newly developed horizontal subsurface-flow constructed wetland. Journal of Environmental Management, v. 147, p. 349-355, 2015. https://doi.org/ 10.1016/j.jenvman.2014.09.025 
Vymazal, J. Removal of nutrients in various types of constructed wetlands. Science of the Total Environment, v. 380, n. 1/3, p.48-65, 2007. https://doi.org/10.1016/ j.scitotenv.2006.09.014

Watharkar, A. D.; Khandare, R. V.; Waghmare, P. R.; Jagadale, A. D.; Govindwar, S. P.; Jadhav, J. P. Treatment of textile effluent in a developed phytoreactor with immobilized bacterial augmentation and subsequent toxicity studies on Etheostoma olmstedi fish. Journal of Hazardous Materials, v. 283, p.698-704, 2015. https://doi.org/10.1016/ j.jhazmat.2014.10.019 